\title{
Resistance to Pratylenchus brachyurus in Vitis species population through multivariate
}

\section{approaches and mixed models}

\author{
Paulo Ricardo dos Santos ${ }^{1(0)}$, Alexandre Pio Viana ${ }^{*}{ }^{*}$, Vicente Martins Gomes ${ }^{2}$, Sandra da Costa Preisigke ${ }^{1(0)}$, Odimar Ferreira de

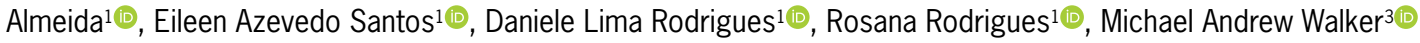

\author{
'Universidade Estadual do Norte Fluminense Darcy Ribeiro/ \\ CCTA- Lab. de Melhoramento Genético Vegetal, Av. Alberto \\ Lamego,2000 - 28013-602 - Campos dos Goytacazes, \\ RJ - Brasil. \\ 2Instituto Federal Fluminense, R. Cambuci, km 5 - 28430- \\ 000 - Três Irmãos, RJ - Brasil. \\ ${ }^{3}$ University of California - Dept. of Viticulture \& Enology, One \\ Shields Av. - 95616-5270 - Davis, CA -USA. \\ *Corresponding author <pirapora@uenf.br>
}

Edited by: Leonardo Oliveira Medici

Received December 07, 2017

Accepted May 18, 2018
ABSTRACT: Genetically diverse interspecific hybrids of Vitis were selected for resistance to Pratylenchus brachyurus. Three segregating populations with 57 hybrid crosses were evaluated. The parents included Vitis romanetiiC166-043 × 07355-075, 06354-047 × Cereza and 06354$047 \times$ Nocera, selected from the germplasm bank at the University of California, Davis, the United States. The experiment was arranged in a randomized block design, with three replications and three plants per plot. Root mass, nematodes per gram of root and reproduction factor were determined and used as quantitative variables; 16 multi categoric descriptors were also evaluated. The traits were analyzed using the Ward-Modified Location Model procedure (WardMLM) for the composition of genotype groups. Genetic parameters and prediction of genetic values by Restricted Maximum Likelihood / Best Linear Unbiased Prediction (REML / BLUP) were assessed. The Ward-MLM classification strategy supported the formation of three homogeneous groups. Group I comprised 13 hybrids; Group II, 26 hybrids; and Group III, 18 hybrids. Groups II and III contained hybrids resistant to $P$. brachyurus. High broad sense heritability values were found for root mass, reproduction factor and nematodes per gram of root, which provided genetic gain and allowed selection of resistant genotypes available for cloning, since the total genetic variance occurred due to the dominance effects. Of the 57 genotypes assessed, those with the lowest genotypic values for reproduction factor were selected as resistant, including: $\mathrm{CH} 3.2$, $\mathrm{CH} 3.23, \mathrm{CH} 3.8, \mathrm{CH} 3.37, \mathrm{CH} 3.38, \mathrm{CH} 3.41, \mathrm{CH} 3.36, \mathrm{CH} 2.1, \mathrm{CH} 2.7, \mathrm{CH} 1.1, \mathrm{CH} 1.3$ and $\mathrm{CH} 1.2$. Keywords: Vitis genotypes, nematode, root, genetic variability

\section{Introduction}

In the international scenario, the Brazilian viticulture occupied the $11^{\text {th }}$ place in grape production and the $13^{\text {th }}$ in wine production in 2015, accounting for a total production of 1.6 million tons of grapes in 2016 (FAO, 2016). Therefore, viticulture in Brazil has huge social and economic importance for generating employment and income, considering both table grapes and wine production (IBGE, 2016).

However, nematodes seriously impair grapevine establishment by hindering development, decreasing vigor and greatly reducing the plant root system, thereby decreasing fruit yield and quality. It is estimated that nematode feeding reduces annual grape production by 20 to $25 \%$ worldwide (Puerari et al., 2012). The specie Pratylenchus brachyurus stands out for its wide dissemination in regions of agriculture cultivation. It has been recognized as one of the worst soil-borne pests of grapevines, especially under high populations in the soil (Téliz et al., 2007; Ferris et al., 2012).

The increase in population levels and damage caused by $P$. brachyurus represent a serious problem for production systems, compromising tropical viticulture (Puerari et al., 2012). The application of nematicides as a control method is an expensive and inefficient practice. The use of resistant genotypes is the main strategy for nematodes control in the vine, as it does not increase production costs, nor does it harm the environment.
Therefore, the selection of resistant hybrids is necessary to be used as rootstocks for good yield in viticulture (Walker et al., 1994; Zasada et al., 2012).

The inclusion of wild species in breeding programs is one of the key approaches to pest and disease resistance breeding, since these species may have resistance genes not found in cultivated plants. Therefore, knowing the genetic variability to select resistant clones in segregating populations is particularly important for breeders when the level of variation in breeding populations is not fully known or explored (Walker et al., 2010; Viana et al., 2011).

This study aimed to characterize populations of interspecific crosses of Vitis based on qualitative and quantitative descriptors and estimate genetic parameters capable of selecting interspecific hybrids resistant to $P$. brachyurus for grapevine breeding programs.

\section{Materials and Methods}

\section{Populations assessed}

Three segregating populations with 57 hybrids obtained from crosses involving Vitis spp. were investigated in relation to their resistance to $P$. brachyurus (Table 1).

\section{Experimental details and phenotyping}

Cuttings of hybrids were rooted and then planted in $7 \mathrm{~L}$ pots containing a soil: sand mixture atratio2:1 (v/v) and kept in a greenhouse in the municipality of Campos dos Goytacazes, Rio de Janeiro, Brazil (21 $44^{\prime}$ S, $41^{\circ} 19^{\prime}$ 
Table 1 - Parents and crosses used in the morphological characterization and evaluation for resistance to P. brachyurus at the University of California, Davis, USA.

\begin{tabular}{|c|c|}
\hline Parents $^{\mathrm{a}}$ & Traits \\
\hline 07355-075 (V. vinifera) & Advanced wine grape selection with resistance to Pierce's disease originating from V. arizonica \\
\hline Vitis romanetii C166-043 (V. romanetii) & Chinese species, DVIT2732, from the National Clonal Germplasm Repository - Davis \\
\hline Nocera (V. vinifera) & An Italian wine grape from Sicily \\
\hline Cereza (V. vinifera) & Large berried Italian table grape \\
\hline 06354-047 (V. vinifera/M. rotundifolia) & Powdery mildew resistant wine grape selection with resistance from a $V$. vinifera $\times$ Muscadinia rotundifolia hybrid \\
\hline Crosses & Number of hybrids assessed \\
\hline Vitis romanetii C166-043 × 07355-075 & $7-\mathrm{CH}^{\mathrm{a}}$ \\
\hline 06354-047 ×Cereza & $9-\mathrm{CH}^{\mathrm{a}}$ \\
\hline 06354-047 ×Nocera & $41-\mathrm{CH}^{\mathrm{a}}$ \\
\hline Total & 57 \\
\hline
\end{tabular}

${ }^{\mathrm{a}} \mathrm{CH} 1, \mathrm{CH} 2$ and $\mathrm{CH} 3=$ hybrid obtained from crossed 1,2 and 3 respectively.

$\mathrm{W}$, altitude $12 \mathrm{~m})$, with average temperature and relative humidity of $31.3{ }^{\circ} \mathrm{C}$ and $83 \%$, respectively. Meteorological data were obtained from a thermo-hygrometer inside the greenhouse.

The experiment was arranged in a randomized block design, with three replications and three plants per plot of 57 interspecific Vitis hybrids, and a maize cultivar, 'BR 106', which was used as source of inoculum and as a susceptible control to verify the viability of nematode inoculum. Maize is very sensitive to $P$. brachyurus infestation and cultivar 'BR 106' was used in this work for its wide distribution in commercial crops throughout Brazil.

After four months (in Nov 2015), the plants were inoculated with a suspension of 800 adults and juveniles of $P$. brachyurus. The nematode suspension was calibrated to 400 nematodes $\mathrm{mL}^{-1}$ and placed into two evenly distributed holes around the grape and maize seedlings.

Maize was evaluated approximately 90 days after inoculation for nematode extraction. After that, each pot received a new plant to be evaluated in 180 days for grapes and a second 90 days for maize again. The root systems of grape and maize plants were collected for nematode extraction. Nematodes were extracted from the roots using the methodology proposed by Coolen and D'Herde (1972). The samples obtained were evaluated and all the specimens of $P$. brachyurusin each sample were counted under a stereoscopic microscope, using the Peters's counting slide.

From the evaluations, we determined the root fresh mass, nematodes per gram of root and the reproduction factor $(R F=P f / P i$, where $F R, P f$ and $P i$ refer to the reproduction factor, final population and initial population, respectively). The plants were classified as immune $(F R=0)$, resistant $(0<F R<1)$ and moderately resistant or susceptible $(F R>1)$, as described by Oostenbrink (1966). Fresh root mass was determined from the plants were carefully removed to the pots and the separate aerial part of the root system. The root systems were washed in running water, the roots were placed on absorbent paper until water excess was removed, then they were weighed and fresh root mass was obtained.
The interspecific hybrids were also characterized by morphological descriptors. Sixteen qualitative descriptors were used (vegetative stage) along with three quantitative characters related to $P$. brachyurus resistance, for 19 descriptors (Table 2). Ampelographic characters were described by using OIV descriptors (OIV, 2013) with small modifications. Sixteen parameters were observed and most of them were measured in different organs of the adult plant (Table 2). These characters were observed ten days after inoculations in plants of each plot (three plants), where five young and adult leaves were measured per plant and the statistic mode was calculated for each plant.

\section{Ward-MLM multivariate analysis}

The quantitative and qualitative variables were analyzed simultaneously, using the Ward-MLM procedure to compose genotype groups, using the procedure CLUSTER and IML in SAS program (Statistical Analysis System, version 9.2). The distance matrix was obtained by the Gower algorithm (Gower, 1971) using the Ward grouping method. The ideal number of groups was defined according to the pseudo- $\mathrm{F}$ and pseudo- $\mathrm{t}^{2}$ criteria, combined with the likelihood profile and the likelihood ratio test.

The Gower dissimilarity index was used because the set of variables in the study form a mixed group of qualitative and quantitative traits in which a single index of dissimilarity is generated, ranging from 0 to 1 . Finally, a complete MLM analysis was carried out for the number of groups (g) defined, which described the classification results on a table presenting the groups formed, while a canonical analysis was used for the quantitative variables. To obtain the canonical variables, the CANDISC procedure in SAS program was used, which contained the canonical coordinates for observations (Crossa and Franco, 2004).

\section{Estimates of genetic parameters and individual selection using the REML/BLUP procedure}

To select the representative value of a clone, genotypic values for each quantitative trait were obtained 
Table 2 - Descriptors used for the characterization and assessment of a population from the interspecific cross in Vitis spp. UENF, Campos dos Goytacazes, Rio de Janeiro, Brazil, 2016

\begin{tabular}{|c|c|}
\hline Descriptors & Description \\
\hline \multicolumn{2}{|l|}{ Qualitative } \\
\hline Young branch: opening in the tip; & 1 = closed; 3 = semi-open; 5 = fully open \\
\hline Young branch: Anthocyanin pigmentation in the tip; & $1=$ absent or very weak; $3=$ weak $;=$ medium; $7=$ strong; $9=$ very strong \\
\hline Young leaf: color of the upper limb face; & $\begin{array}{l}1=\text { yellow-green; } 2=\text { green with anthocyanic areas; } 3=\text { clear red-copper; } 4=\text { dark } \\
\text { red-copper; } 5=\text { wine-red }\end{array}$ \\
\hline Adult leaf: limbsize; & $1=$ very small; $3=$ small; $5=$ medium; $7=$ large $; 9=$ very large \\
\hline Adult leaf: limbshape; & $1=$ cordiform; $2=$ deltoid; $3=$ pentagonal; $4=$ orbicular $; 5=$ reniform \\
\hline Adult leaf: number of lobes; & $1=$ none $; 2=$ three $; 3=$ five $; 4=$ seven; $5=$ above seven \\
\hline Adult leaf: depth of the upper lateral sinuses; & $3=$ shallow $5=$ medium; $7=$ deep \\
\hline Adult leaf: arrangement of the lobes of the upper lateral sinuses; & 1 = open; 2 = closed; 3 = slightly overlapped; 4 = very overlapped \\
\hline Adult leaf: shape of the basis of the petiolar sinus; & $1=$ concave (in " $\mathrm{u}^{\prime}$ ); 2 = straight (in " $\mathrm{v}$ "); 3 = convex \\
\hline Adult leaf: arrangement of the lobes of the petiolar sinus; & $\begin{array}{l}1=\text { fully open; } 2=\text { very open; } 3=\text { half open; } 4=\text { little open; } 5=\text { closed; } 6=\text { slightly } \\
\text { overlapped; } 7=\text { half overlapped; } 8=\text { very overlapped; } 9=\text { fully overlapped }\end{array}$ \\
\hline Adult leaf: length of teeth; & $3=$ short $5=$ medium; $7=$ long \\
\hline Adult leaf: teeth length / width ratio; & $1=$ very small; $3=$ small $5=$ medium; $7=$ large; $9=$ very large \\
\hline Adult leaf: teethshape & $\begin{array}{l}1=\text { both sides are concave; } 2=\text { both sides are rectilinear; } 3=\text { both sides are convex; } \\
4=\text { one side is concave and the other is convex; } 5=\text { combination of both sides are } \\
\text { rectilinear with both sides are convex }\end{array}$ \\
\hline Adult leaf: anthocyanin pigmentation of major veins on upper limb face & $1=$ absent or very weak; $3=$ weak; $5=$ medium; $7=$ strong; $9=$ very strong \\
\hline Adult leaf: length of petiole in relation to central vein; & $4=$ shorter $; 5=$ equal; $6=$ longer \\
\hline Adult leaf: density of erect hairs on the petiole & $1=$ absent or very low; $3=$ low; $5=$ medium; $7=$ high; $9=$ very high \\
\hline \multicolumn{2}{|l|}{ Quantitative } \\
\hline Root Mass (g) & Total mass root system of plants 180 days after inoculation \\
\hline Reproduction Factor & Ratio between final population and initial population of nematodes \\
\hline Nematodes per gram of root & $\begin{array}{l}10 \mathrm{~g} \text { of roots were weighed and separated and chopped to determine nematode } \\
\text { numbers }\end{array}$ \\
\hline
\end{tabular}

using the REML (Restricted Maximum Likelihood) procedure and applied to the mixed linear model in its matrix form to evaluate related clones in randomized block designs with several plants per plot: $Y=X r+Z a+Z d$ $+W p+e$. Where: $Y$ is the data vector; $r=$ is the vector of repetition effects (assumed to be fixed) added to the general average; $a=$ is the vector of the additive genetic effects (assumed to be random); $d=$ is the vector of the dominance genetic effects (assumed to be random); $p=$ is the vector of plot effects (assumed to be random); $e$ $=$ is the vector of errors or residuals (assumed to be random). Capital letters refer to incidence matrices for these effects.

The following genetic parameters were estimated: additive genetic variance $\left(\sigma_{a}^{2}\right)$, dominance genetic variance $\left(\sigma_{d}^{2}\right)$, environmental variance between plots $\left(\sigma_{\text {parc }}^{2}\right)$, residual (environmental) variance $\left(\sigma_{e}^{2}\right)$, individual phenotypic variance $\left(\sigma_{f}^{2}\right)$, narrow sense individual heritability $\left(\hat{h}_{a}^{2}\right)$, individual heritability of dominance effects $\left(\hat{h}_{d}^{2}\right)$, broad sense individual heritability $\left(\hat{h}_{g}^{2}\right)$, coefficient of determination of plot effects $\left(c_{\text {parc }}^{2}\right)$ and overall average of the experiment. by:

The structures of averages and variances are given

$$
E\left[\begin{array}{l}
y \\
a \\
d \\
c \\
e
\end{array}\right]=\left[\begin{array}{l}
X b \\
0 \\
0 \\
0 \\
0
\end{array}\right]
$$

$$
\operatorname{Var}\left[\begin{array}{l}
y \\
a \\
d \\
c \\
e
\end{array}\right]=\left[\begin{array}{ccccc}
V & Z A \sigma_{a}^{2} & Z D \sigma_{D}^{2} & W I \sigma_{c}^{2} & I \sigma_{e}^{2} \\
A \sigma_{a}^{2} Z^{\prime} & A \sigma_{a}^{2} & 0 & 0 & 0 \\
D \sigma_{d}^{2} Z^{\prime} & 0 & D \sigma_{d}^{2} & 0 & 0 \\
I \sigma_{a}^{2} W^{\prime} & 0 & 0 & I \sigma_{c}^{2} & 0 \\
I \sigma_{a}^{2} & 0 & 0 & 0 & I \sigma_{e}^{2}
\end{array}\right]
$$

where: $V=Z A \sigma_{a}^{2} Z^{\prime}+Z D \sigma_{d}^{2} Z^{\prime}+W I \sigma_{c}^{2}+I \sigma_{e}^{2}$

Mixed Model Equations:

$$
\left[\begin{array}{cccc}
X^{\prime} X & X^{\prime} Z & X^{\prime} Z & X^{\prime} W \\
Z^{\prime} X & Z^{\prime} Z+A^{-1} \lambda_{2} & Z^{\prime} Z & Z^{\prime} W \\
Z^{\prime} X & Z^{\prime} Z & Z^{\prime} Z+D^{-1} \lambda_{2} & Z^{\prime} W \\
W^{\prime} X & W^{\prime} Z & W^{\prime} Z & W^{\prime} W+I \lambda_{3}
\end{array}\right]=\left[\begin{array}{c}
\hat{b} \\
\hat{a} \\
\hat{d} \\
\hat{c}
\end{array}\right]=\left[\begin{array}{c}
X^{\prime} y \\
Z^{\prime} y \\
Z^{\prime} y \\
W^{\prime} y
\end{array}\right]
$$

where:

$\lambda_{1}=\frac{\sigma_{e}^{2}}{\sigma_{a}^{2}}=\frac{1-h_{e}^{2}-c^{2}}{h^{2}} ;$

$\lambda_{2}=\frac{\sigma_{e}^{2}}{\sigma_{d}^{2}}=\frac{1-h_{a}^{2}-c^{2}}{h_{a}^{2}-h^{2}}$;

$\lambda_{3}=\frac{\sigma_{e}^{2}}{\sigma_{c}^{2}}=\frac{1-h_{e}^{2}-c^{2}}{c^{2}}$

$\sigma_{d}^{2}$ and $h_{a}^{2}$ : Genetic variance of dominance and broad sense heritability, respectively; D: matrix of genetic correlation of dominance between the individuals assessed. 
The system provided predictions of the additive $(\hat{a})$ and dominance $(\hat{d})$ effects isolatedly. The total genotypic values, given by $\hat{g}=\hat{a}+\hat{d}$, can be predicted directly from the equations of mixed models:

$$
\left[\begin{array}{ccc}
X^{\prime} X & X^{\prime} Z & X^{\prime} W \\
Z^{\prime} X & Z^{\prime} Z+G^{-1} \sigma_{E}^{2} & Z^{\prime} Z \\
W^{\prime} X & W^{\prime} Z & W^{\prime} W+I \lambda_{3}
\end{array}\right]=\left[\begin{array}{c}
\hat{b} \\
\hat{g} \\
\hat{c}
\end{array}\right]=\left[\begin{array}{l}
X^{\prime} y \\
Z^{\prime} y \\
W^{\prime} y
\end{array}\right]
$$

where: $G=\sigma_{a}^{2}+D \sigma_{d}^{2}$

Iterative estimators of variance components by REML via EM algorithm:

$$
\begin{aligned}
& \hat{\sigma}_{e}^{2}=\left[y^{\prime} y-\hat{b}^{\prime} X^{\prime} y=\hat{a}^{\prime} Z^{\prime} y-\hat{d}^{\prime} Z^{\prime} y-\hat{c}^{\prime} W^{\prime} y\right] /[N-r(x)] \\
& \hat{\sigma}_{c}^{2}=\left[\hat{c}^{\prime} \hat{c}+\hat{\sigma}_{e}^{2} \operatorname{tr} C^{44}\right] / s \\
& \hat{\sigma}_{a}^{2}=\left[a^{\prime} A^{-1}-\hat{a}^{\prime}++\hat{\sigma}_{e}^{2} \operatorname{tr}\left(A^{-1} C^{22}\right)\right] / q ; \\
& \hat{\sigma}_{d}^{2}=\left[\hat{d}^{\prime D^{-1}}-\hat{d}+\hat{\sigma}_{e}^{2} \operatorname{tr}\left(D^{-1} C^{22}\right)\right] / q . \\
& \text { Results }
\end{aligned}
$$

\section{Results}

\section{Ward-MLM multivariate analysis}

The Ward-MLM classification strategy, which simultaneously used quantitative traits related to resistance to $P$. brachyurus and qualitative, such as morphological and agronomic descriptors, defined the optimal number in three groups and was capable of discriminating 57 interspecific hybrids (Figure 1). The likelihood function was used to determine the ideal number of groups, with an increment value of 66.51 (Figure1). According to Barbé et al. (2010), the analysis of the likelihood function can define accurate criteria for formation of groups, resulting in less subjective groups.

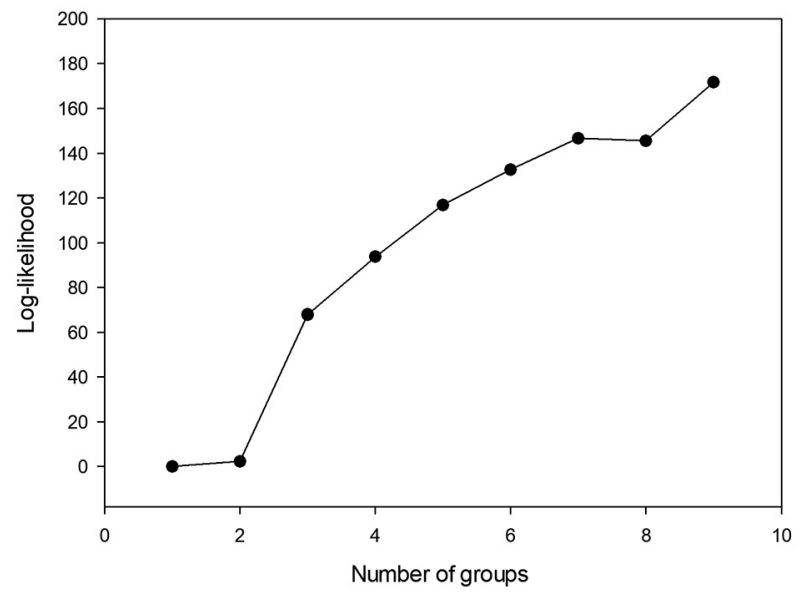

Figure 1 - Logarithmic probability function (Log-likelihood) for the number of groups formed by Ward-Modified Location Model procedure (Ward-MLM) strategy in interspecific hybrids of Vitis spp. UENF, Campos dos Goytacazes, Rio de Janeiro, Brazil, 2016.
The traits of young shoot tips showed that most hybrids presented opening of shoot tips, with predominance of hybrids presenting absent and weak anthocyanic pigmentation $(70 \%)$. Only group II contained four hybrids with strong anthocyanin pigmentation (Table 3).

Considering the traits evaluated in the adult leaves, hybrids of group I presented between zero and three lobes, whereas hybrids of groups II and III had predominantly between three and five lobes (91\%). Limb-shaped leaves were predominantly adeltoid (73\%) with upper lateral sinus ranging from shallow to deep. For the base shape of the petiole sinuses, most hybrids in each group presented leaves of the rectilinear type. Hybrids of groups I and II had leaflet size ranging from small to very large, while group III allocated hybrids with predominantly small leaf limbs (13 hybrids) (Table $3)$.

For the traits evaluated in adult leaves, hybrids had zero to five lobes, adeltoid-shaped leaves, shallowto-deep superior lateral sinuses, petiolar sinuses ranging from concave, convex to rectiliniear, and limb sizes ranging from very small to very large (Table 3).

Regarding the variables related to resistance to $P$. brachyurus for the susceptible control, maize 'BR 106', the average values obtained for root mass, number of nematodes per gram of root and reproduction factor were $74.87,86.58$ and 29.40, respectively, confirming viability of the inoculum used in this work (Table 6).

Wide variation in the quantitative variables related to $P$. brachyurus resistance was detected among the hybrids evaluated (Table 4). Group I had 13 genotypes with the highest values for reproduction factor and nematodes per gram of root, but lower values for root mass. The minimum value for the reproduction factor of this group was 4.09 and the number of nematodes per gram of roots was 21.74. All hybrids were susceptible to high nematode reproduction rates and reproduction factors above 1.0. The susceptible hybrids had the highest values for this trait. One hybrid in this group was from cross $V$. romanetii C166-043 $\times$ 07355-075, two from cross 06354-047 $\times$ Cereza, and ten from cross 06354-047 $\times$ Nocera.

Most genotypes (26 hybrids) were clustered in Group II. Five were obtained from cross $V$. romanetii C166-043 × 07355-075; five, from cross 06354-047 $\times$ Cereza; and 16, from cross 06354-047 × Nocera. Some resistant genotypes had reproduction factors equal to 0.7. None of the hybrids was considered highly resistant to $P$. brachyurus, given that nematodes were found in root systems of these hybrids and their reproduction factors were higher than zero (Table 4).

Group III had 18 genotypes, five were resistant with the minimum reproduction factor of 0.35 . Most hybrids in this group belong to $06354-047 \times$ Nocera population (15 hybrids) and the other hybrids, from crosses 06354-047 $\times$ Cereza (two hybrids) and Vitis romanetii C166-043 × 07355-075 (one hybrid). Groups II and III were the most homogeneous, with an average reproduc- 
Table 3 - Traits and number of interspecific hybrids per group of multicategoric traits in each of the three groups formed by the Ward-MLM strategy. UENF, Campos dos Goytacazes, Rio de Janeiro, Brazil, 2016

\begin{tabular}{|c|c|c|c|}
\hline \multirow{2}{*}{ Descriptors } & \multicolumn{3}{|c|}{ Groups } \\
\hline & G I (13) & G II (26) & G III (18) \\
\hline \multicolumn{4}{|c|}{ Young branch: openness in the tip } \\
\hline Closed & - & 6 & 3 \\
\hline Open & 13 & 20 & 15 \\
\hline \multicolumn{4}{|c|}{ Young branch: anthocyanin pigmentation of the tip } \\
\hline Absent or weak & 11 & 16 & 13 \\
\hline Medium & 2 & 6 & 5 \\
\hline Strong & - & 4 & - \\
\hline \multicolumn{4}{|c|}{ Young Leaf: color of the upper limb face } \\
\hline Yellow-green & 1 & 6 & 6 \\
\hline Green with anthocyanicareas & 10 & 19 & 11 \\
\hline Light copperred & 1 & 1 & 1 \\
\hline Darkcopperred & 1 & - & - \\
\hline Winered & - & - & - \\
\hline \multicolumn{4}{|l|}{ Adult leaf: limbshape } \\
\hline Cordiform & 3 & 2 & 2 \\
\hline Deltoid & 8 & 21 & 13 \\
\hline Pentagonal & 2 & 3 & 3 \\
\hline Orbicular & - & - & - \\
\hline Reniform & - & - & - \\
\hline \multicolumn{4}{|l|}{ Adult leaf: number of lobes } \\
\hline None & 4 & - & - \\
\hline Three & 9 & 11 & 11 \\
\hline Five & - & 14 & 7 \\
\hline Seven & - & - & - \\
\hline Above seven & - & 1 & - \\
\hline \multicolumn{4}{|c|}{ Adult leaf: depth of the upper lateral sinuses } \\
\hline Shallow & 2 & 5 & 7 \\
\hline Medium & 6 & 12 & 7 \\
\hline Deep & 5 & 9 & 4 \\
\hline \multicolumn{4}{|c|}{ Adult leaf: arrangement of the upper lateral sinuses } \\
\hline Open & 10 & 17 & 12 \\
\hline Closed & 3 & 8 & 5 \\
\hline Very overlapped & - & 1 & 1 \\
\hline Slightly overlapped & - & - & - \\
\hline \multicolumn{4}{|c|}{ Adult leaf: shape of the basis of the petiolar sinus } \\
\hline Concave (in "u") & 5 & 7 & 1 \\
\hline Rectilinear (in "v") & 6 & 10 & 10 \\
\hline Convex & 2 & 9 & 7 \\
\hline \multicolumn{4}{|c|}{ Adult leaf: arrangement of the lobes of the petiolar sinuses } \\
\hline Fully open & 9 & 10 & 12 \\
\hline Half open & 2 & 13 & 5 \\
\hline Slightly open & 1 & 1 & 1 \\
\hline Closed & 1 & 2 & - \\
\hline Overlapped & - & - & - \\
\hline \multicolumn{4}{|l|}{ Adult leaf: tooth length } \\
\hline Short & 9 & 13 & 14 \\
\hline Medium & 3 & 10 & 3 \\
\hline Long & 1 & 3 & 1 \\
\hline \multicolumn{4}{|c|}{ Adult leaf: tooth length/tooth width ratio } \\
\hline Short & 2 & 6 & 3 \\
\hline Medium & 10 & 17 & 14 \\
\hline
\end{tabular}

\begin{tabular}{|c|c|c|c|}
\hline Large & 1 & 3 & 1 \\
\hline \multicolumn{4}{|l|}{ Adult leaf: size of the limb } \\
\hline Verysmall & - & 1 & 4 \\
\hline Small & 7 & 13 & 13 \\
\hline Medium & 3 & 8 & 1 \\
\hline Large & 2 & 2 & - \\
\hline Verylarge & 1 & 2 & - \\
\hline \multicolumn{4}{|l|}{ Adult leaf: shape of the teeth } \\
\hline Both sides are concave & 2 & 11 & 5 \\
\hline Both sides are rectilinear & 3 & 12 & 9 \\
\hline Both sides are convex & 8 & 1 & 4 \\
\hline One side is concave and the other is convex & - & 2 & - \\
\hline Rectilinear sides with convex sides & - & - & - \\
\hline \multicolumn{4}{|c|}{ Adult leaf: Anthocyanin pigmentation of the major veins in the upper limb } \\
\hline Absentorweak & 7 & 20 & 15 \\
\hline Medium & 5 & 3 & 2 \\
\hline Strong & 1 & 3 & 1 \\
\hline \multicolumn{4}{|c|}{ Adult leaf: length of the petiole in relation to the central vein } \\
\hline Shorter & 7 & 19 & 12 \\
\hline Equal & 5 & 6 & 4 \\
\hline Longer & 1 & 1 & 2 \\
\hline \multicolumn{4}{|l|}{ Adult leaf: Density of erect hairs on the petiole } \\
\hline Absent or low & 8 & 17 & 16 \\
\hline Medium & 4 & 4 & 2 \\
\hline High & 1 & 5 & - \\
\hline
\end{tabular}

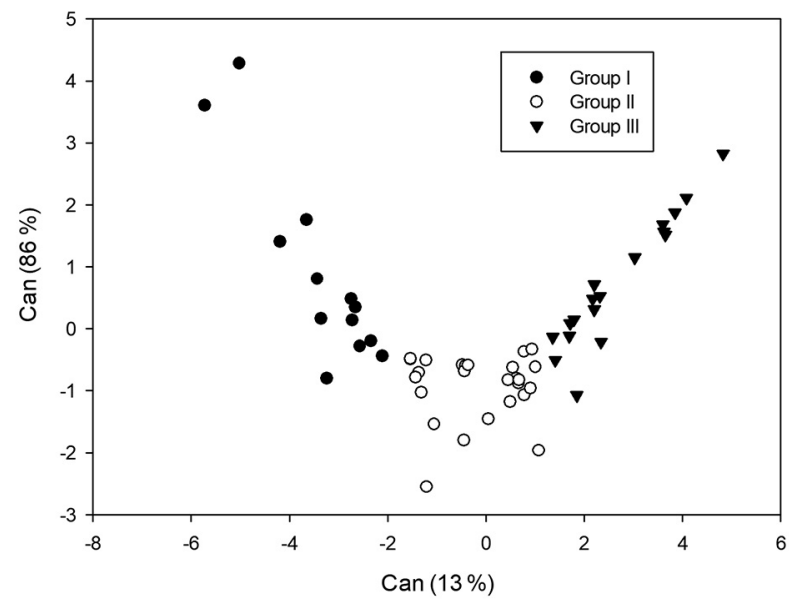

Figure 2 -The first two canonical variables for the three groups formed by the Ward-Modified Location Model procedure (WardMLM). UENF, Campos dos Goytacazes, Rio de Janeiro, Brazil, 2016.

tion factor value of 5.04 and 2.69, and low standard deviation estimate of 2.60 and 2.11 , respectively. The most resistant genotypes with the highest estimates for root mass (100.93 and $120.0 \mathrm{~g}$ ) and the smallest nematode populations (19.95 and 8.82), respectively, were found in these groups. Hybrids with the smallest number of nematodes per gram of root and, consequently, lower reproduction factor, also exhibited a more developed root system, a trait evaluated by root mass (Table 4). 
Table 4 - Minimum and maximum values, average and standard deviation of quantitative traits for each of the three groups and coefficient of correlation of quantitative variables with the first two canonical variables (CAN). UENF, Campos dos Goytacazes Rio de Janeiro, Brazil, 2016

\begin{tabular}{|c|c|c|c|c|c|c|}
\hline \multirow[t]{2}{*}{ Variables } & \multirow{2}{*}{ Parameters } & \multicolumn{3}{|c|}{ Groups } & \multicolumn{2}{|c|}{ CAN } \\
\hline & & G I (13) & $G \|(26)$ & G III (18) & CAN 1 & CAN 2 \\
\hline \multirow[t]{4}{*}{ Root Mass } & Minimum & 65.40 & 71.00 & 100.50 & 1.88 & 1.94 \\
\hline & Maximum & 97.00 & 133.20 & 134.50 & & \\
\hline & Average & 79.80 & 100.93 & 120.0 & & \\
\hline & $\begin{array}{l}\text { Standard } \\
\text { Deviation }\end{array}$ & 9.19 & 15.55 & 10.20 & & \\
\hline \multirow{4}{*}{$\begin{array}{l}\text { Reproduction } \\
\text { Factor }\end{array}$} & Minimum & 4.09 & 0.71 & 0.35 & -1.65 & -6.55 \\
\hline & Maximum & 14.22 & 9.25 & 7.68 & & \\
\hline & Average & 8.34 & 5.04 & 2.69 & & \\
\hline & $\begin{array}{l}\text { Standard } \\
\text { Deviation }\end{array}$ & 3.38 & 2.60 & 2.11 & & \\
\hline \multirow[t]{4}{*}{$\begin{array}{l}\text { Nematodes per } \\
\text { gram of root }\end{array}$} & Minimum & 21.74 & 3.87 & 1.33 & 0.33 & 7.32 \\
\hline & Maximum & 72.00 & 33.64 & 22.80 & & \\
\hline & Average & 41.37 & 19.25 & 8.82 & & \\
\hline & $\begin{array}{l}\text { Standard } \\
\text { Deviation }\end{array}$ & 14.99 & 8.86 & 6.56 & & \\
\hline
\end{tabular}

Table 5 - Distance between the groups formed by the Ward-MLM procedure (proposed by Franco et al., 1998). Data analyzed at UENF, Campos dos Goytacazes, Rio de Janeiro, Brazil, 2016

\begin{tabular}{lccc}
\hline Groups & Group I & Group II & Group III \\
\hline Group I & - & 37.83 & 87.88 \\
Group II & 37.83 & - & 36.11 \\
Group III & 87.88 & 36.11 & - \\
\hline
\end{tabular}

The first two canonical variables (CAN) obtained through the Ward-MLM methodology explained $99 \%$ of the total variation (Figure 2). According to Crossa and Franco (2004), if the first two canonical variables result in estimates above $80 \%$ for the total variation, a satisfactory interpretation of variability of hybrids can be obtained, which was achieved in this study. This allowed an appropriate two-dimensional graphic presentation of relationships between groups and hybrids within the groups.

Based on the first canonical variable, the traits that mostly contributed to the quantification of genetic divergence were root mass, with 1.88 , and reproduction factor, -1.65 (Table 4). A separation between Groups I and III formed by the Ward-MLM procedure and approximation of Groups I and II and between Groups II and III was observed (Table 5 and Figure 2). Groups II and III include resistant hybrids with the smallest nematode populations in the roots.

During the experiment, susceptible plants presented symptomatic reactions, such as necrotic lesions of various sizes and colors in the vine roots infested with $P$. brachyurus. In addition, several symptoms were detected on shoots of susceptible plants, including loss of vigor, varying plant size, yellowing and premature leaf drop, wilt during the hottest hours of the day, slow growth, necrotic leaves and plant death due to its inability to produce an adequate root system. Such symptomatic reactions are typical of the genus Pratylenchus in grapevines (Zheng et al., 2010; Zasada et al., 2012).

Table 6 - Estimates of variance components and genetic parameters for variables: root mass (g), reproduction factor, and nematodes per gram of root. Data from 57 clones of Vitis spp. interspecific populations selected for resistance to nematode $P$. brachyurus. Data acquired and analyzed at UENF, Campos dos Goytacazes, Rio de Janeiro, Brazil, 2016

\begin{tabular}{|c|c|c|c|}
\hline \multirow{2}{*}{$\begin{array}{l}\text { Variancecomponents } \\
\text { (Individual REML)* }^{*}\end{array}$} & \multicolumn{3}{|c|}{ Traits } \\
\hline & Root Mass & Reproduction Factor & Nematodes per root gram \\
\hline$\sigma_{a}^{2 a}$ & 13.1238 & 0.5622 & 11.2973 \\
\hline$\sigma_{a}^{2 b}$ & 401.5690 & 24.7453 & 500.8805 \\
\hline$\sigma_{p l o t s}^{2}$ & 0.0955 & 0.0167 & 0.2839 \\
\hline$\sigma_{e}^{2 d}$ & 141.4035 & 4.4519 & 114.3441 \\
\hline$\sigma_{f}^{2 e}$ & 556.1918 & 29.7760 & 626.8058 \\
\hline$\hat{h}_{a}^{2 f}$ & 0.0236 & 0.0188 & 0.0180 \\
\hline$\hat{h}_{g}^{2 g}$ & $0.7456 \pm 0.1495$ & $0.8499 \pm 0.1596$ & $0.817 \pm 0.1565$ \\
\hline$\hat{h}_{d}^{2 h}$ & 0.7220 & 0.8310 & 0.7991 \\
\hline$C_{\text {plots }}^{2}$ & 0.002 & 0.006 & 0.005 \\
\hline Overall meanpopulation & 104. 0917 & 6.1129 & 19. 5720 \\
\hline BR 106 mean & 74.87 & 29.40 & 86.58 \\
\hline
\end{tabular}




\section{Estimates of genetic parameters and individual selection using REML / BLUP procedure}

Estimates of coefficient of broad sense heritability that captured the total genotypic effects were higher than $74 \%$ for root mass, reproduction factor and nematodes per gram of root, especially for the reproduction factor $(84 \%)$ having the highest value (Table 6). The high values for these traits show great potential for genetic progress in the selection of individuals resistant to $P$. brachyurus.

Estimates of genetic variances were primarily derived from dominance effects for root mass (401.57), reproduction factor (24.745) and nematodes per gram of root (500.881). Consequently, the individual heritability of dominance was increased, ranging from 0.722 to 0.831 . Such values are close to estimates of broad sense heritabilities (Table 6). The narrow sense individual heritabilities were low for the three traits, ranging from 0.018 to 0.024 , as evidenced by low estimates of additive variances, reaching values up to 13.124 for root mass (Table 6).

Considering phenotypic variances of root mass (556.192), reproduction factor (29.776) and nematodes per gram of roots (626.806), dominance variances were higher than residuals, ranging from 4,452 (reproduction factor) to 141,404 (root mass). These values corroborate that these conditions are favorable for selection and demonstrate that most parts of the phenotypes are attributed to genetic causes of dominance effects (Table 6).

Determination coefficients of plot effects ranged from 0.002 to 0.006 for all traits. The low values of these coefficients are attributed to very small environmental variations within the plots and indicate good experimental precision, corroborated by low estimates of environmental variance between the plots, ranging from 0.096 to 0.284 (Table 6).

A significant different was observed for genotypic values of hybrids for the reproduction factor of nematodes, which ranged from 0.63 to 18.48 (Table 7). The following hybrids stand out for the selection of resistant individuals based on their genotypic values $/ \mathrm{u}+$ g): $\mathrm{CH} 3.2, \mathrm{CH} 3.23, \mathrm{CH} 3.8, \mathrm{CH} 3.37, \mathrm{CH} 3.38, \mathrm{CH} 3.41$ and $\mathrm{CH} 3.36$ from cross 06354-047 $\times$ Nocera; CH2.1 and $\mathrm{CH} 2.7$, from cross 06354-047 $\times$ Cereza; and CH1.1, CH1.3 and CH1.2 from cross 06354-047 $\times$ Nocera.

\section{Discussion}

Based on the pseudo-F and pseudo-t 2 criteria, the likelihood function defined that the ideal number of homogeneous groups is three. These groups were formed according to their similarities, which is mainly due to the greater increase in the likelihood function observed for group III, that is, 65.54 (Figure 1).

The likelihood function was used to define more accurate criteria for the formation of the three groups, which resulted in more objective groupings than the hierarchical grouping methods in which the number of groups is established in a more subjective manner (Gonçalves et al., 2008; Kurosawa et al., 2017).

For most hybrids allocated to each group formed, there was predominance of hybrids with leaves with weak anthocyanin pigmentation in the main veins of the upper limb. However, $35 \%$ of the hybrids had pigmentation varying from medium to strong levels. Similarly, $29 \%$ of these hybrids had anthocyanin pigmentation varying from medium to strong levels in the young branches (Table 3). In red grapes, high concentration of anthocyanins in leaves and branches are important for production of juice and red wine, because anthocyanins contribute to sensory attributes and mainly to color and flavor. However, quantity and composition of these anthocyanins differ according to species, variety, phenological stage and climate (Muñoz-Espada et al., 2004).

The knowledge of morphological traits assessed in this work (Table 2, Figure 2) is fundamental for plant breeding programs. These traits may not play a direct role in selection and development of new wine grapes; however, they do contribute to a better characterization of genetic diversity, exploration of genetic variability and subsequent conservation of species.

Vitis hybrids were separated into three groups according to their genotypic values that reactto $P$. brachyurus. Regarding the trait reproduction factor $(\mathrm{RF}): 46$ genotypes were susceptible $(\mathrm{RF} \geq 1)$; seven were moderately resistant $(1.0 \geq \mathrm{RF}<1.5)$; and four, resistant $(\mathrm{RF}$ $\leq 1)$. Eleven moderately resistant and resistant hybrids selected corresponded to $19 \%$ of the total segregating populations (Table 7). Resistant hybrids derived from crosses that used 06354-047 as a parent, indicating that it may be the source of resistance to $P$. brachyurus.

Groups I and II had resistant hybrids; however, neither was immune to nematodes. The hybrids selected in our study have a dual application, that is, both for direct use as rootstocks or development of fruiting varieties.

Heritability is one of the most important genetic parameters, as it quantifies the fraction of the inheritable phenotypic variation available for selection. Nematodes per gram of root and root mass allow the best genetic progress of broad sense heritability for the traits of reproduction factor. In addition, since the results found that these traits are correlated, there is a good chance of success in advancing all three characters through selection of the reproduction factor alone (Santos et al., 2017; Santos et al., 2015;Kouassi et al., 2009).The sexual reproduction of these hybrids is not likely to provide significant genetic gains for these traits in grape breeding. However, genetic gains can be maximized (Kouassi et al., 2009; Piepho et al., 2009) by selecting hybrids for lower reproduction factor and nematodes per gram of root as well as by cloning the material selected. The number of nematodes per gram of fresh roots is a good parameter to assess nematode populations, since it correlates directly with losses caused by nematodes (Starr et al., 2002). 
Table 7 - Arrangement of 57 interspecific hybrids of Vitis spp. for resistance to nematode $P$. brachyurus: where (a) refers to predicted additive effects, (d) predicted dominance effects, ( $g$ ) predicted genotypic effects, $(\mathrm{u}+\mathrm{g})$ genotypic average, genetic gain, and new average or genotypic values for trait reproduction factor in the selection of hybrids. Data acquired and analyzed at UENF, Campos dos Goytacazes, Rio de Janeiro, Brazil, 2016

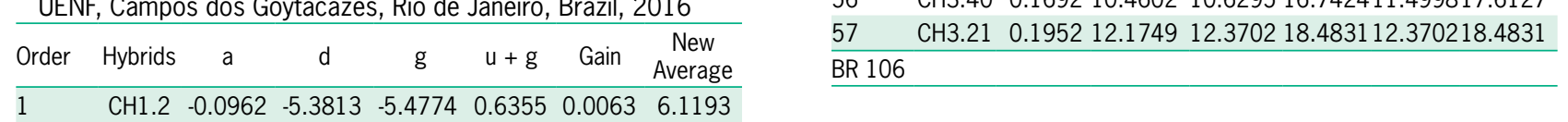
$\begin{array}{llllllll}\mathrm{CH} 2.7 & -0.0631 & -5.1453 & -5.2083 & 0.9046 & 0.2043 & 6.3172\end{array}$ $\begin{array}{lllllll}\mathrm{CH} 3.38 & -0.0663 & -5.0817 & -5.1479 & 0.965 & 0.3045 & 6.4174\end{array}$ $\begin{array}{lllllll}\mathrm{CH} 1.3 & -0.0905 & -5.003 & -5.0935 & 1.0194 & 0.4074 & 6.5203\end{array}$ $\begin{array}{lllllll}\mathrm{CH} 3.37 & -0.0642 & -4.9428 & -5.0069 & 1.106 & 0.5132 & 6.6261\end{array}$ $\begin{array}{lllllll}\mathrm{CH} 1.1 & -0.0891 & -4.911 & -5.0001 & 1.1129 & 0.6214 & 6.7343\end{array}$ $\begin{array}{lllllll}\mathrm{CH} 3.8 & -0.0633 & -4.8855 & -4.9488 & 1.1641 & 0.7338 & 6.8468\end{array}$ $\begin{array}{llllllll}\mathrm{CH} 2.1 & -0.0584 & -4.8349 & -4.8932 & 1.2197 & 0.8498 & 6.9627\end{array}$ $\begin{array}{lllllll}\mathrm{CH} 3.23 & -0.0605 & -4.7036 & -4.7641 & 1.3488 & 0.9694 & 7.0824\end{array}$ $\begin{array}{llllllll}\mathrm{CH} 3.2 & -0.0597 & -4.6493 & -4.7091 & 1.4039 & 1.0914 & 7.2044\end{array}$ $\begin{array}{lllllll}\text { CH3.41 } & -0.0493 & -3.9642 & -4.0136 & 2.0993 & 1.2175 & 7.3305\end{array}$ $\begin{array}{lllllll}\mathrm{CH} 3.6 & -0.0423 & -3.499 & -3.5413 & 2.5716 & 1.3338 & 7.4467\end{array}$ $\begin{array}{lllllll}\mathrm{CH} 3.1 & -0.0371 & -3.1594 & -3.1966 & 2.9164 & 1.4446 & 7.5575\end{array}$ $\begin{array}{lllllll}\text { CH3.9 } & -0.0358 & -3.0694 & -3.1052 & 3.0077 & 1.5525 & 7.6654\end{array}$ $\begin{array}{llllllll}\mathrm{CH} 3.5 & -0.0333 & -2.9085 & -2.9418 & 3.1711 & 1.6634 & 7.7763\end{array}$ $\begin{array}{llllllll}\mathrm{CH} 3.13 & -0.031 & -2.7517 & -2.7827 & 3.3302 & 1.7757 & 7.8887\end{array}$ $\begin{array}{lllllll}\mathrm{CH} 3.16 & -0.0259 & -2.4205 & -2.4464 & 3.6665 & 1.8897 & 8.0026\end{array}$ CH3.32 $-0.0255 \quad-2.3936 \quad-2.4192 \quad 3.6937 \quad 2.0009 \quad 8.1138$ $\begin{array}{lllllll}\mathrm{CH} 3.3 & -0.0236 & -2.2642 & -2.2878 & 3.8252 & 2.1172 & 8.2301\end{array}$ $\begin{array}{lllllll}\mathrm{CH} 3.30 & -0.0215 & -2.1252 & -2.1467 & 3.9663 & 2.2363 & 8.3492\end{array}$ $\begin{array}{lllllll}\mathrm{CH} 2.2 & -0.0166 & -2.0788 & -2.0954 & 4.0175 & 2.358 & 8.4709\end{array}$ CH3.24 $-0.0119-1.4905 \quad-1.5024 \quad 4.6106 \quad 2.4852 \quad 8.5982$ CH3.34 $-0.0081 \quad-1.2407 \quad-1.2488 \quad 4.8641 \quad 2.6025 \quad 8.7155$ $\begin{array}{lllllll}\mathrm{CH} 3.10 & -0.0066 & -1.1472 & -1.1539 & 4.9591 & 2.7192 & 8.8322\end{array}$ $\begin{array}{lllllll}\mathrm{CH} 3.27 & -0.0041 & -0.9821 & -0.9863 & 5.1267 & 2.8403 & 8.9532\end{array}$ $\begin{array}{lllllll}\mathrm{CH} 3.25 & -0.0031 & -0.916 & -0.9192 & 5.1938 & 2.9637 & 9.0766\end{array}$ $\begin{array}{lllllll}\text { CH3.12 } & 0.0041 & -0.4376 & -0.4335 & 5.6794 & 3.0931 & 9.2061\end{array}$ $\begin{array}{lllllll}\mathrm{CH} 3.7 & 0.0046 & -0.4028 & -0.3981 & 5.7148 & 3.2147 & 9.3277\end{array}$ $\begin{array}{lllllll}\mathrm{CH} 3.28 & 0.0048 & -0.3936 & -0.3889 & 5.7241 & 3.3438 & 9.4567\end{array}$ $\begin{array}{lllllll}\mathrm{CH} 3.35 & 0.0054 & -0.3493 & -0.3439 & 5.7691 & 3.482 & 9.5949\end{array}$ $\begin{array}{lllllll}\mathrm{CH} 3.20 & 0.0055 & -0.3467 & -0.3412 & 5.7717 & 3.6292 & 9.7421\end{array}$ $\begin{array}{lllllll}\mathrm{CH} 3.14 & 0.0143 & 0.2382 & 0.2526 & 6.3655 & 3.788 & 9.9009\end{array}$ $\begin{array}{lllllll}\mathrm{CH} 2.9 & 0.0187 & 0.2505 & 0.2692 & 6.3821 & 3.9353 & 10.0482\end{array}$ $\begin{array}{lllllll}\mathrm{CH} 2.6 & 0.0202 & 0.3503 & 0.3705 & 6.4834 & 4.0947 & 10.2076\end{array}$ $\begin{array}{lllllll}\mathrm{CH} 2.5 & 0.0264 & 0.7609 & 0.7873 & 6.9003 & 4.264 & 10.3769\end{array}$ $\begin{array}{llllllll}\mathrm{CH} 1.4 & -0.0023 & 0.8154 & 0.8131 & 6.9261 & 4.4295 & 10.5424\end{array}$ $\begin{array}{lllllll}\mathrm{CH} 3.18 & 0.0243 & 0.8952 & 0.9195 & 7.0324 & 4.6103 & 10.7233\end{array}$ $\begin{array}{lllllll}\mathrm{CH} 3.31 & 0.0273 & 1.0956 & 1.1229 & 7.2359 & 4.8046 & 10.9175\end{array}$ $\begin{array}{lllllll}\mathrm{CH} 3.4 & 0.0299 & 1.2661 & 1.296 & 7.409 & 5.0091 & 11.1221\end{array}$ $\begin{array}{lllllll}\mathrm{CH} 3.22 & 0.0371 & 1.7385 & 1.7756 & 7.8885 & 5.2275 & 11.3405\end{array}$ $\begin{array}{llllllll}\mathrm{CH} 1.5 & 0.0128 & 1.8131 & 1.8259 & 7.9388 & 5.4433 & 11.5562\end{array}$ $\begin{array}{lllllll}\mathrm{CH} 1.3 & 0.0258 & 2.6683 & 2.6941 & 8.8071 & 5.6845 & 11.7974\end{array}$ $\begin{array}{lllllll}\mathrm{CH} 3.15 & 0.0532 & 2.7998 & 2.853 & 8.9659 & 5.898 & 12.011\end{array}$ $\begin{array}{lllllll}\mathrm{CH} 3.11 & 0.0542 & 2.8685 & 2.9227 & 9.0356 & 6.1323 & 12.2452\end{array}$ $\begin{array}{lllllll}\mathrm{CH} 2.4 & 0.0599 & 2.9672 & 3.0271 & 9.14 & 6.3997 & 12.5127\end{array}$ $\begin{array}{lllllll}\mathrm{CH} 3.26 & 0.0601 & 3.256 & 3.316 & 9.429 & 6.7064 & 12.8193\end{array}$ $\mathrm{CH} 3.17 \quad 0.0765 \quad 4.3423 \quad 4.4188 \quad 10.53177 .045413 .1583$ CH3.29 $0.0779 \quad 4.4319 \quad 4.5098 \quad 10.62277 .337213 .4502$

\begin{tabular}{lrrrrrrr}
50 & $\mathrm{CH} 3.33$ & 0.082 & 4.702 & 4.7839 & 10.8969 & 7.6907 & 13.8036 \\
51 & $\mathrm{CH} 3.39$ & 0.0863 & 4.9862 & 5.0725 & 11.1854 & 8.1059 & 14.2188 \\
52 & $\mathrm{CH} 1.7$ & 0.0636 & 5.1635 & 5.2271 & 11.34 & 8.6115 & 14.7244 \\
53 & $\mathrm{CH} 2.3$ & 0.1144 & 6.5668 & 6.6812 & 12.7941 & 9.2884 & 15.4013 \\
54 & $\mathrm{CH} 2.8$ & 0.1266 & 7.3685 & 7.4951 & 13.608 & 9.9401 & 16.0531 \\
55 & $\mathrm{CH} 3.19$ & 0.1489 & 9.117 & 9.2659 & 15.378810 .755216 .8681 \\
56 & $\mathrm{CH} 3.40$ & 0.1692 & 10.4602 & 10.6295 & 16.742411 .499817 .6127 \\
57 & $\mathrm{CH} 3.21$ & 0.1952 & 12.1749 & 12.3702 & 18.4831 & 12.370218 .4831 \\
\hline BR 106 & & & & & & \\
\hline
\end{tabular}

In this work, the conditions are favorable for selection since most phenotypes are attributed to genetic causes. The total phenotypic variances tended towards zero, due to the environmental effect between plots and determination coefficients of plot effects. Thus, it can be concluded that there is a small magnitude effect of plots and good selection efficiency regarding experimental precision for reproduction factor, root mass and nematode per gram of root (Santos et al., 2017).

For selection, using the average components predicted by BLUP, plant breeders should prioritize genotypic values, as these are necessary predicted true values (Piepho et al., 2009). Thus, selected hybrids should have average reproduction factors of up to 1.40 (Table 7).The use of reproduction factor for selection demonstrated that most hybrids are susceptible since they had reproduction factor values higher than 1.0. However, for several hybrids, the genetic values $(\mathrm{u}+\mathrm{g})$ for reproduction factor ranged from 1.0 to2.0. In these cases, it is advisable to consider susceptibility as moderate resistance, since they are genotypes that allow nematode survival, without showing strong symptoms of their feeding. The same is applied to resistance found in hybrid $\mathrm{CH} 3.38$, whose genetic value was slightly less than 1.0 for reproduction factor.

On the other hand, several hybrids, with reproduction factor values above or very close to 2.0 should be considered susceptible. These individuals are efficient hosts and favor the establishment of $P$. brachyurus populations that are high enough to cause significant direct damage to grapevine growth and prevent their use in breeding programs.

Narrow sense heritability for root mass, nematodes per gram of root and reproduction factor were less than $2 \%$ or almost null for these traits. This reveals that for grapevine breeding, selection for resistance to $P$. brachyurus by sexual reproduction in a population composed of these clones does not lead to genetic gains and is therefore impracticable. While in the broad sense, considering the additive and dominant variances, where heritabilities $\left(\hat{h}_{g}^{2 g}\right)$ reached values ranging from 74 to $84 \%$, meaning that selection based on these traits and cloning the selected material can be maximized the genetic gains. In other words, broad sense heritability relative to traits of root mass, nematodes per gram of root and reproduction factor had the greatest genetic advances associated to the cloning of selected genotypes for those traits. The indi- 
viduals selected for resistance in this study had the lowest genotypic values, with predicted gains below $1 \%$. Hybrid $\mathrm{CH} 1.2 \mathrm{had}$ the lowest genotypic value for reproduction factor $(\mathrm{u}+\mathrm{g}=0.6355)$ and genetic gain close to zero (0.0063). This indicates that genotypes with lower values for reproduction factor can be cloned and advanced.

The use of resistant grapevines, along with other measures of nematode control, decreases $P$. brachyurus populations in the soil and increases commercial yield of vineyards. Resistant clones can now be evaluated for use as fruiting varieties or as commercial rootstocks (Walker etal., 1994).

\section{Conclusions}

The Ward-MLM classification strategy effectively discriminated among the variable genotypes and allowed the separation of 57 genotypes into three homogeneous groups. Groups II and III were the closest genetically and contained hybrids resistant to P. brachyurus. High estimates of dominance variance suggest that further genetic progress can be achieved through the cloning of resistant hybrids, more than their use as resistant parents. Based on the genotypic values for reproduction factor, the following resistant and moderately resistant clones were selected: $\mathrm{CH} 3.2, \mathrm{CH} 3.23, \mathrm{CH} 3.8, \mathrm{CH} 3.37, \mathrm{CH} 3.38$, $\mathrm{CH} 3.41, \mathrm{CH} 3.36, \mathrm{CH} 2.1, \mathrm{CH} 2.7, \mathrm{CH} 1.1, \mathrm{CH} 1.3$ and $\mathrm{CH} 1.2$. The hybrids with the lowest nematode populations per gram of root and lower breeding capacity for $P$. brachyurus resistance should be tested as rootstocks and evaluated for use in infested areas.

\section{Acknowledgements}

We are thankful to FAPERJ - Fundação de Amparo à Pesquisa do Estado do Rio de Janeiro for the granting and CAPES, of the doctoral scholarship and financial support provided to the first author, as well as to the Conselho Nacional de Desenvolvimento Científico e Tecnológico (CNPq) for the accomplishment of the present work.

\section{Authors' Contributions}

Conceptualization: Santos, P.R.; Viana, A.P.; Gomes, V.M.; Walker M.A. Data acquisition: Santos, P.R.; Preisigke, S.C.; Almeida, O.F.; Rodrigues, D.L.; Data analysis: Santos, P.R.; Viana, A.P.; Design of Methodology: Santos, P.R.; Viana, A. P.; Gomes, V.M.; Rodrigues, R.; Software development: Santos, P.R.; Viana, A.P.; Writing and editing: Santos, P.R.; Viana, A.P.; Santos, E.A.; Rodrigues, R.; Walker M. A.

\section{References}

Barbé, T.C.; Amaral Júnior, A.T.; Gonçalves, L.S.A.; Rodrigues, R.; Scapim, C.A. 2010. Association between advanced generations and genealogy in inbred lines of snap bean by the Ward-Modifie Location Model. Euphytica 173: 337-343.
Coolen, W.A.; D'Herde, C.J. 1972. A method for the Quantitative Extraction of Nematodes from Plant Tissue. State Agricultural Research Centre, Ghent, Belgium.

Crossa, J.; Franco, J. 2004. Statistical methods for classifying genotypes. Euphytica 137: 19-37.

Ferris, H.; Zheng, L.; Walker, M.A. 2012. Resistance of grape rootstocks to plant-parasitic nematodes. Journal of Nematology 44: 377-386.

Food and Agriculture Organization [FAO]. 2016. FAOSTAT. FAO, Rome, Italy. Available at: http://faostat.fao.org/default.aspx [Accessed Mar 28, 2018]

Franco, J.; Crossa, J.; Villasenõr, J.; Taba, S. 1998. Classifying genetic resources by categorical and continuous variables. Crop Science 38: 1688-1696.

Gonçalves, L.S.; Rodrigues, R.; Amaral Júnior, A.T.; Karasawa, M.; Sudré, C.P. 2008. Comparison of multivariate statistical algorithms to cluster tomato heirloom accessions. Genetic and Molecular Research 7: 1289-1297.

Gower, J.C. 1971. A general coefficient of similarity and some of its properties. Biometrics 27: 857-874.

Brazilian Institute of Geography and Statistics [IBGE]. 2016. Agricultural Census. = Instituto Brasileiro de Geografia e Estatística. Censo Agropecuário. Available at: https://cidades. ibge.gov.br/brasil/pesquisa/15/11863 [Accessed Mar 28, 2018] (in Portuguese).

International Organisation of Vine and Wine [OIV]. 2013. International list of vine varieties and their synonyms. OIV, Paris, France. Available at: http://www.oiv.int/public/ medias/2274/code-2e-edition-finale.pdf [Accessed 27 Mar, 2018]

Kouassi, A.B.; Durel, C.; Costa, F.; Tartarini, S.; Weg, E.V.; Evans, K; Fernandez-Fernandez, F.; Govan, C.; Boudichevskaja, A.; Dunemann, F.; Antofie, A.; Lateur, M.; Stankiewicz-Kosyl, M.; Soska, A.; Tomala, K.; Lewandowski, M.; Rutkovski, K.; Zurawicz, E.; Guerra, W.; Laurens, F. 2009. Estimation of genetic parameters and prediction of breeding values for apple fruit-quality traits using pedigreed plant material in Europe. Tree Genetics and Genomes 5: 659-672.

Kurosawa, R.N.; Amaral Junior, A.T.; Silva, F.H.; Santos, A.; Vivas, M.; Kamphorst, S.H.; Pena, G.F. 2017. Multivariate approach in popcorn genotypes using the Ward-MLM strategy: morpho-agronomic analysis and incidence of Fusarium spp. Genetic and Molecular Research 16: 1-12

Muñoz-Espada, A.C.; Wood, K.V.; Bordelon, B.; Watkins, B.A. 2004. Anthocyanin quantification and radical scavening capacity of Concord, Norton, and Marechalfoch grapes and wines. Journal of Agricultural Food Chemistry 52: 67796786.

Oostenbrink, M. 1966. Major Characteristics of the Relation Between Nematodes and Plants. Beltsville, MD, USA.

Piepho, H.P.; Möhring, J.; Melchinger, A.E.; Büchse, A. 2009. BLUP for phenotypic selection in plant breeding and variety testing. Euphytica 161: 209-228.

Puerari, H.H.; Dias-Arieira, C.R.; Moura, M.F; Biela, F.; Chiamolera, F.M.; Cunha, T.P.L. 2012. Reaction of grape vine rootstocks to Pratylenchus brachyurus and Pratylenchus zeae. Tropical Plant Pathology 37: 220-222. 
Santos, E.A.; Viana, A.P.; Freitas, J.C.O.; Rodrigues, D.L.; Tavares, R.F.; Paiva, C.L.; Souza, M.M. 2015. Genotype selection by REML/BLUP methodology in a segregating population from an interspecific Passiflora spp. crossing. Euphytica 204: 1-11.

Santos, P.R.; Preisigke, S.C.; Viana, A.P.; Cavalcante, N.R.; Bezerra, C.M.; Amaral Júnior, A.T. 2017. Associations between vegetative and production traits in guava tree full-sib progenies. Pesquisa Agropecuária Brasileira 52: 303-310.

Starr, J.L.; Cook, R.; Bridge, J. 2002. Plant resistence to parasitic nematodes. CABI, Wallingford, England.

Téliz, D.; Landa, B.B.; Rapoport, H.F.; Pérez Camacho, F.; Jiménez Díaz, R.M.; Castillo, P. 2007. Plant-parasitic nematodes infecting grapevine in southern Spain and susceptible reaction to root-knot nematodes of rootstocks reported as moderately resistant. Plant Disease 91: 1147-1154.

Viana, A.P.; Riaz, S.; Walker, M.A. 2011. Evaluating genetic diversity and optimizing parental selections in a segregating table-grape population. American Journal of Enology and Viticulture 62: 285-290.
Walker, M.A.; Ferris, H.; Eyre, M. 1994. Resistance in Vitis and Muscadiniaspecies to Meloidogyne incognita. Plant Disease 78: 1055-1058.

Walker, M.A.; Aguero, C.; Hwang, C.F.; Zheng, L.; Ferris, H.; Ng, D. 2010. Progress toward the breeding of rotundifolia-based rootstocks. American Journal of Enology and Viticulture 61: 4-31.

Zasada, I.A.; Riga, R.; Pinkerton, J.N.; Wilson, J.H.; Schreiner, R.P. 2012. Plant-parasitic nematodes associated with grapevines, Vitis vinifera, in Washington and Idaho. American Journal of Enology and Viticulture 63: 522-528.

Zheng, L.; Ferris, H; Walker, A.M. 2010. Interactions between nematodes and grape rootstocks. Journal of Nematology 42 : 278-279. 